\title{
Phytochemical Profiling of Lavandula coronopifolia Poir. Aerial Parts Extract and Its Larvicidal, Antibacterial, and Antibiofilm Activity against Pseudomonas aeruginosa
}

\author{
Mahmoud Emam 1,2, Doaa R. Abdel-Haleem ${ }^{3}$, Maha M. Salem ${ }^{2}$, Lina Jamil M. Abdel-Hafez ${ }^{4}$, \\ Rasha R. Abdel Latif ${ }^{2}$, Shaimaa Mahmoud Farag ${ }^{3}$, Mansour Sobeh ${ }^{5, * \mathbb{D}}$ and Mohamed A. El Raey ${ }^{2, * \mathbb{D}}$ \\ 1 College of Pharmaceutical Science \& Collaborative Innovation Center of Yangtze River Delta Region Green \\ Pharmaceuticals, Zhejiang University of Technology, Hangzhou 310014, China; me.hegazy@nrc.sci.eg \\ 2 Phytochemistry and Plant Systematics Department, National Research Centre, Dokki, Giza 12622, Egypt; \\ maha_abdelmejed@yahoo.com (M.M.S.); rasharefaat38@yahoo.com (R.R.A.L.) \\ 3 Department of entomology, Faculty of Science, Ain Shams University, Abbasia, Cairo 11566, Egypt; \\ doaaramadan@sci.asu.edu.eg (D.R.A.-H.); shaimaa.mahmoudfarag@sci.asu.edu.eg (S.M.F.) \\ 4 Department of Microbiology and Immunology, Faculty of Pharmacy, October 6 University, 6th October City, \\ Giza 12585, Egypt; linajamil@o6u.edu.eg \\ 5 AgroBioSciences Research Division, Mohammed VI Polytechnic University, Lot 660-Hay MoulayRachid, \\ 43150 Ben-Guerir, Morocco \\ check for \\ updates \\ * Correspondence: mansour.sobeh@um6p.ma (M.S.); ma.aziz@nrc.sci.eg (M.A.E.R.)
}

Citation: Emam, M.; Abdel-Haleem, D.R.; Salem, M.M.; Abdel-Hafez, L.J.M.; Latif, R.R.A.; Farag, S.M.; Sobeh, M.; El Raey, M.A. Phytochemical Profiling of Lavandula coronopifolia Poir. Aerial Parts Extract and Its Larvicidal, Antibacterial, and Antibiofilm Activity against Pseudomonas aeruginosa. Molecules 2021, 26, 1710. https://doi.org/ $10.3390 /$ molecules 26061710

Academic Editors: Manuela Pintado, Ezequiel Coscueta and María Emilia Brassesco

Received: 20 February 2021

Accepted: 15 March 2021

Published: 19 March 2021

Publisher's Note: MDPI stays neutral with regard to jurisdictional claims in published maps and institutional affiliations.

Copyright: (c) 2021 by the authors. Licensee MDPI, Basel, Switzerland. This article is an open access article distributed under the terms and conditions of the Creative Commons Attribution (CC BY) license (https:// creativecommons.org/licenses/by/ $4.0 /)$.

\begin{abstract}
Infections associated with the emergence of multidrug resistance and mosquito-borne diseases have resulted in serious crises associated with high mortality and left behind a huge socioeconomic burden. The chemical investigation of Lavandula coronopifolia aerial parts extract using HPLC-MS/MS led to the tentative identification of 46 compounds belonging to phenolic acids, flavonoids and their glycosides, and biflavonoids. The extract displayed larvicidal activity against Culex pipiens larvae ( $\mathrm{LC}_{50}=29.08 \mu \mathrm{g} / \mathrm{mL}$ at $72 \mathrm{~h}$ ). It significantly inhibited cytochrome P-450 monooxygenase (CYP450), acetylcholinesterase (AChE), and carboxylesterase (CarE) enzymes with the comparable pattern to the control group, which could explain the mode of larvae toxification. The extract also inhibited the biofilm formation of Pseudomonas aeruginosa by $17-38 \%$ at different Minimum Inhibitory Concentrations (MICs) $(0.5-0.125 \mathrm{mg} / \mathrm{mL})$ while the activity was doubled when combined with ciprofloxacin (ratio $=1: 1 \mathrm{v:v}$ ). In conclusion, the wild plant, L. coronopifolia, can be considered a promising natural source against resistant bacteria and infectious carriers.
\end{abstract}

Keywords: Lavandula coronopifolia; Culex pipiens; larvicidal; antibiofilm formation; LC-MS/MS; molecular networking

\section{Introduction}

Mosquito vector-borne diseases are considered a global problem, which highlights the necessity for new prospects and cost-effective agents for vector control. Around 100 species of mosquitoes transmit viral and bacterial disorders such as malaria, lymphatic filariasis, dengue, and yellow fever, affecting several millions of people worldwide. In 2017, WHO recorded the highest mortality and morbidity due to mosquito-borne disorders that affect human health and economic society. Therefore, the development of novel mosquito repellents and antibacterial agents to overcome the microbial resistance threat is highly demanded. This could also help to avoid disrupting the ecological balance [1-3]. Plant secondary metabolites could furnish safe, efficacious, and multi-mechanistic candidates that might be useful as insecticidal and antibacterial agents.

The genus Lavandula (commonly known as lavender) comprises 45 species that are mainly distributed in subtropical and tropical regions [4,5]. Plants of the genus have been used in folk medicine since ancient times to treat pain, headache, migraine, and 
antiepileptic, antidiuretic, antirheumatic, and carminative agents. They become famous for their multiple uses in different pharmaceuticals, aroma, and food products [6,7]. The phytochemistry of the genus is centered on mono- and sesquiterpenoids, together with traces of alkaloids, and phenolic structures [7].

Lavandula coronopifolia Poir. (Arabic: Khozama) is a shrublike perennial, growing in the rocky environment and desert plains mainly distributed in subtropical and tropical regions [8]. The first attention to L. coronopifolia traces back to 1999, when El-Garf et al. isolated and identified numerous hydroxyl flavones such as hypolaetin, isoscutellarien, and luteolin from its dried aerial parts [4]. Then, several studies reported the presence of polyhydroxyoleanolic acids, polyhydroxyursolic acids and their glycosides, caffeic acid, rosmarinic acid, rutin, quercetin, and hesperidin $[9,10]$.

L. coronopifolia showed a plethora of substantial biological activities. These include antioxidant [11], antimicrobial [12], $\alpha$-glucosidase inhibitory [10], and hepatoprotective [13] activities. These activities were attributed to the presence of flavonoids, especially flavones and their glucuronides, in addition to triterpenes $[9,10]$. Moreover, L. coronopifolia essential oils possessed substantial antibacterial activity against the Gram-negative bacteria and methicillin-resistant Staphylococcus aureus bacteria [14].

In this work, we comprehensively characterized the phytoconstituents of the aerial parts of L. coronopifolia extract by HPLC-MS/MS and confirmed the existence of possible skeletons quantitatively using ${ }^{1} \mathrm{H}-\mathrm{NMR}$ and molecular networking. We also evaluated the insecticidal activities against Culex pipiens larvae and the antibiofilm formation activity against isolates of Pseudomonas aeruginosa. We explored several biochemical parameters to investigate the mechanism of the insecticidal activities.

\section{Material and Methods}

\subsection{Plant Material, Extraction, and Preliminary Qualitative Analysis}

Lavandula coronopifolia Poir. was collected from the Western Desert of Egypt in March 2018. A voucher sample was placed at the international herbarium of the National Research Centre (CAIRC) (S.N: 1023). The plant aerial parts (250 g) were crushed into small pieces and then extracted by dipping into 70\% MeOH: $\mathrm{H}_{2} \mathrm{O}(v: v)$ at ambient temperature for one week. The solution was filtered (Whatman no. 1), then concentrated till dryness using Rotavapor $^{\circledR}$ (Heizbad Hei-VAP, Heidolph, Germany), yielding $28.45 \mathrm{~g}$, and stored at $4{ }^{\circ} \mathrm{C}$ for further experiments. The L. coronopifolia extract was screened for its phyto-constituents as flavonoids (Shinoda's test), phenolics ( $\mathrm{FeCl}_{3}$ test), ellagitannins $\left(\mathrm{NaNO}_{2}\right.$ assay), and gallotannins $\left(\mathrm{KIO}_{3}\right.$ test) $[15,16]$. The proton NMR (Jeol ECA-500 MHz, Japan) experiment using DMSO-d6 was done for the total extract.

\section{2. $\mathrm{HPLC}-\mathrm{MS} / \mathrm{MS}$}

HPLC-PDA-MS ${ }^{n}$ mass spectra was performed through a ThermoFinnigan (Thermo Electron Corporation, Austin, TX, USA) LC system coupled with a mass spectrometer (LCQ-Duo ion trap) having an ESI source (ThermoQuest, Thermo Scientific, Waltham, MA, USA) [15]. The injection process, flow rate, elution solvents, resolution, and negative MS operating parameters were described previously [17]. In brief, a Zorbax Eclipse XDB-C18, rapid resolution, $150 \times 4.6 \mathrm{~mm}, 3.5 \mu \mathrm{m}$ column was used (Agilent, Santa Clara, CA, USA). A gradient consisting of water and acetonitrile (ACN), each having $0.1 \%$ formic acid, was applied, and ACN was increased from 5\% to 30\% within $60 \mathrm{~min}$ and then to $90 \%$ within the next $30 \mathrm{~min}$ at a flow rate of $1 \mathrm{~mL} / \mathrm{min}$ and a 1:1 split before the ESI source [17].

\subsection{Molecular Networking Workflow Description}

The mgf formatting mass file was uploaded to the online platform of GNPS (http: / / gnps.ucsd.edu) (accessed on 27 June 2020). Then the data were filtered as described previously and the visualization of molecular networking (MNW) workflow was carried out using Cytoscape 3.6.1 software [15,18]. 


\subsection{Larvicidal Assay}

\subsubsection{Insects}

A laboratory susceptible strain of Culex pipiens was obtained from the Research and Training Center on Vectors of Diseases (RTC), Ain Shams University. It was colonized in the entomology department insectary at $27 \pm 2{ }^{\circ} \mathrm{C}, 75 \pm 5 \%$ relative humidity (RH), and a $14 \mathrm{~h} / 10 \mathrm{~h}$ light/dark photoperiod following standard procedures [19]. The larvae were reared in enamel dishes containing $2000 \mathrm{~mL}$ of distilled water. Newly hatched larvae were fed on Tetra-Min, Germany. Adults were reared in $(30 \times 30 \times 30 \mathrm{~cm})$ wooden cages and provided with $10 \%$ sucrose solution daily, as well as a pigeon for female blood feeding.

\subsubsection{Bioassay}

The larvicidal activity was evaluated against the third larval instar of $C$. pipiens under the same controlled laboratory conditions. The bioassay was assessed using the standard method described in [20]. The extract was dissolved in water to prepare the stock solution. Batches of 25 of 3 rd instar larvae of $C$. pipiens were transferred by a plastic dropper to small disposable test cups and treated with different concentrations of the extract $(10,25,50,100$, 150 , and $200 \mu \mathrm{g} / \mathrm{mL}$ prepared in distillated water) and control with distillated water only, in a triplicate manner. Mortality was recorded after 24,48 , and $72 \mathrm{~h}$ post treatment.

\subsubsection{Preparation of Samples for Biochemical Assay}

The 3rd larval instar of $C$. pipiens was treated by $\mathrm{LC}_{50}$ values, and then the insects were prepared as described by Amin et al. [21]. The whole bodies of larvae were homogenized in distilled water $(50 \mathrm{mg} / 1 \mathrm{~mL})$. The homogenates were centrifuged at 8000 r.p.m. for $15 \mathrm{~min}$ at $4{ }^{\circ} \mathrm{C}$. The supernatants were used for biochemical analyses. Acetylcholinesterase (AChE) and carboxylesterase assays were measured according to the method described by Simpson et al. [22], using acetylcholine bromide ( $\mathrm{AchBr}$ ) and methyl $\mathrm{n}$ butyrate (MeB) as substrates, respectively. Alpha esterase ( $\alpha$-esterase) activity was determined according to Van Asperen [23] using $\alpha$-naphthyl acetate as substrate. Glutathione S-transferase (GST) catalyzes the conjugation of reduced glutathione (GSH) with 1-chloro 2,4-dinitrobenzene (CDNB) via the -SH group of glutathione. The conjugate S-(2,4-dinitro-phenyl)-L-glutathione could be detected as described by the method of Habig et al. [24]. Cytochrome P-450 monooxygenase activity was determined using $p$-nitroanisole o-demthylation according to the method of Hansen and Hodgson [25] with slight modifications.

\subsection{Microbiological Assay}

\subsubsection{Sample Collection and Identification of Isolated Bacteria}

Clinical isolates of Pseudomonas aeruginosa were collected from burn wounds, otitis media, and urine as previously described [26] and were kept for scientific research. The isolates were grown on Tryptic soya agar (TSA) (Difco ${ }^{\mathrm{TM}}$, Strasbourg, France) for $24 \mathrm{~h}$ at $37^{\circ} \mathrm{C}$, then one single colony of each isolate was inoculated into $2 \mathrm{~mL}$ Tryptic soya broth (TSB) (Difco ${ }^{\mathrm{TM}}$, France) with overnight incubation at $37^{\circ} \mathrm{C}$. The samples were cultivated on Cetrimide agar media, after which the isolated species were identified by morphology (pale yellow colonies on MacConkey and green exopigment on Cetrimide agar), Gram staining (Gram-negative bacilli), and biochemical reactions (oxidase-positive). The Microbact ${ }^{\mathrm{TM}}$ Gram-negative system was implemented in compliance with the manufacturer's protocol (Oxoid, Hampshire, UK). A standard strain of P. aeruginosa (ATCC 12924) was kindly provided by NAMRU as a frozen cultural broth containing $40 \%$ glycerol.

\subsubsection{The Antimicrobial Susceptibility Testing}

The antimicrobial susceptibility testing was done using cup agar diffusion method [27]. The bacterial cultures were adjusted to an optical density (OD) of 0.5 at $600 \mathrm{~nm}$, TSA plates were covered with $100 \mu \mathrm{L}$ of each bacterial isolate, and $5 \mathrm{~mm}$ pores were filled with $100 \mu \mathrm{L}$ of extract dissolved in sterile water at $2.5 \mathrm{mg} / \mathrm{mL}$. The plates were incubated for $24 \mathrm{~h}$ at $37^{\circ} \mathrm{C}$. The zone of inhibitions was measured in $\mathrm{mm}$. 


\subsubsection{Minimum Inhibitory Concentration (MIC)}

MIC is used as the gold standard method for detecting the sensitivity of the organisms to antimicrobial agents [28]. The final concentrations of the extract ranging from 2.5 to $0.0195 \mathrm{mg} / \mathrm{mL}$ were prepared and then added to test tubes containing $1 \mathrm{~mL}$ of sterile TSB media. The bacterial suspensions with OD 0.5 at $600 \mathrm{~nm}$ were diluted 1:100 $(\approx 106 \mathrm{CFU} / \mathrm{mL})$, and then $50 \mu \mathrm{L}$ of inoculums were added to each tube. The tubes were incubated at $37^{\circ} \mathrm{C} \pm 2{ }^{\circ} \mathrm{C}$ for $24 \mathrm{~h}$. A tube containing TSB broth without extract was taken as control. The MIC was defined as the lowest concentration of the tested extract that restricted the visible growth of tested strains compared to the blank [29].

\subsubsection{Minimal Bactericidal Concentration (MBC)}

The minimal bactericidal concentration $(\mathrm{MBC})$ was determined by the Petri dish sowing method [30]. This procedure was dependent on the procedures for the determination of MIC. After the incubation period for the determination of the MIC, an aliquot of $0.1 \mathrm{~mL}$ was taken from each of the test tubes that were not showing growth, and then was inoculated into a TSA agar plate. The plates were then incubated at a temperature of $37 \pm 2{ }^{\circ} \mathrm{C}$ for $24 \mathrm{~h}$. After this period, the presence of bacterial colonies was observed in each plate. The $\mathrm{MBC}$ was defined as the lowest concentration of the plant extract that was able to prevent microbial growth in a culture medium (formation of bacterial colonies). The bioassays were performed in duplicate with three repetitions for each bacterial isolate.

\subsubsection{Biofilm Formation Assay and Quantification}

The biofilms were assayed as described in [31,32] using sterile 96-well microtiter plates, each well containing $180 \mu \mathrm{L}$ TSB broth and $20 \mu \mathrm{L}$ of bacterial suspension with OD 0.5 at $600 \mathrm{~nm}$. After $24 \mathrm{~h}$ incubation at appropriate conditions, all the planktonic cells were removed, and the biofilms were gently washed twice with phosphate buffer saline (PBS) to remove any free-floating bacteria. The biofilm cells formed in each well were stained with $200 \mu \mathrm{L}$ crystal violet $(0.1 \% w / v)$ and incubated at room temperature $\left(28^{\circ} \mathrm{C}\right)$ for $10 \mathrm{~min}$. The stain was removed and washed with distilled water for 30-60 s. After 5 min of air drying, the biofilms were solubilized by $200 \mu \mathrm{L}$ of $98 \%$ ethanol, then the optical densities of stained adherent biofilms were measured at $620 \mathrm{~nm}$ using a microplate reader. The evaluation of biofilm production was categorized according to the criteria of Stepanovic et al. as follows: OD $\leq$ ODc: not a biofilm producer (non-adherent); ODc < OD $\leq 2 \mathrm{ODc}$ : a weak biofilm producer (weakly adherent); $2 \mathrm{ODc}<\mathrm{OD} \leq 4 \mathrm{ODc}$ : a moderate biofilm producer (moderately adherent); 4ODc < OD: a strong biofilm producer (strongly adherent). ODc and OD were defined as the mean OD of the blank wells and wells with biofilm, respectively [33].

\subsubsection{Biofilm Inhibition Assay}

The ability of the extract to inhibit the biofilms of the clinical isolates of P. aeruginosa was evaluated according to Stepanović et al. [34] with some modifications. Microbial biofilms were developed in a round-bottom 96-well microtiter plate. Each clinical isolate was inoculated into each well of the 96-well microtiter plate. The extract was added to each well at $1 / 2,1 / 4$, and $1 / 8 \mathrm{MICs}$ and incubated for $24 \mathrm{~h}$ at $37^{\circ} \mathrm{C}$. After the incubation period, non-adherent cells were detached by dipping each sample three times in sterile PBS. The samples were fixed for one hour, and the biofilms were stained with $0.1 \%$ solution of crystal violet in $\mathrm{H}_{2} \mathrm{O}$. After staining, the samples were washed with distilled $\mathrm{H}_{2} \mathrm{O}$ (DW). The measurable biofilm production was achieved by adding $125 \mu \mathrm{L}$ of $30 \%$ acetic acid to de-stain the samples. Afterwards, the OD at $620 \mathrm{~nm}$ was detected using the microplate reader. The percentage (\%) of inhibition formula is as follows:

$$
\% \text { Inhibition }=\frac{\text { Abs control }- \text { Abs sample }}{\text { Abs control }} \times 100
$$




\subsubsection{Combination of the Extract with Ciprofloxacin}

The ability of ciprofloxacin/extract (1:1) to inhibit the biofilm of the strong biofilm isolate of $P$. aeruginosa was evaluated according to Stepanović et al. [34] with some modifications. Microbial biofilms were developed in a round-bottom 96-well microtiter plate. The clinical isolate $\mathrm{C} 4$ was inoculated into each well of the 96 -well microtiter plate, and ciprofloxacin/extract (1:1) was added to each well at 1/2,1/4, and 1/8 MICs and incubated for $24 \mathrm{~h}$ at $37^{\circ} \mathrm{C}$. After incubation $(24 \mathrm{~h})$, non-adherent cells were detached by dipping each sample three times in sterile PBS. The samples were fixed for $1 \mathrm{~h}$, and the biofilms were stained with $0.1 \%$ solution of crystal violet in $\mathrm{H}_{2} \mathrm{O}$. After staining, the samples were washed with DW (distilled $\mathrm{H}_{2} \mathrm{O}$ ). The quantitative analysis of biofilm production was achieved by adding $125 \mu \mathrm{L}$ of $30 \%$ acetic acid to de-stain the samples. Afterwards, the OD at $620 \mathrm{~nm}$ was measured using the microplate reader. The percentage (\%) of inhibition formula is as follows:

$$
\% \text { Inhibition }=\frac{\text { Abs control }- \text { Abs sample }}{\text { Abs control }} \times 100
$$

\subsection{Statistical Analysis}

The biofilm formation inhibiting activities of different concentrations of the extract were compared by two-way ANOVA (Bonferroni post hoc tests). $p<0.05$ was used to detect the significance of differences. The obtained larvicidal data were analyzed using a statistics package (LDP-line) for goodness of fit (chi square test) and to detect $\mathrm{LC}_{50}$ and $\mathrm{LC}_{95}$ values with corresponding $95 \%$ confidence limits (CL), slope, correlation coefficient and standard error. The results of biochemical determinations were investigated by one-way analysis of variance (ANOVA) using Costat statistical software (Cohort software, Berkeley). When the ANOVA statistics were significant $(p<0.01)$, the means were compared by the Duncan's multiple range test [35]. GraphPad Prism 5.0 software (GraphPad Prism Software Inc., San Diego, CA, USA) was used to draw most of the figures.

\section{Results and Discussion}

\subsection{Phytochemical Screening and LC-MS/MS Profile of L. coronopifolia}

The preliminary phytochemical screening of L. coronopifolia extract revealed the presence of dihydroxy phenolics and flavonoids and/or their glycosides, as well as the absence of ellagic and gallotannins moieties. The mass spectrometry analysis (full scan and product ion scan mode) provided structural information of 46 metabolites, including organic and phenolic acids, flavonoids and their glycosides, and bioflavonoids (Table 1 and Figure 1).

\subsection{Molecular Networking (MNW) of L. coronopifolia Aerial Parts' Metabolite Perception}

The symmetrical chemical entities were facilitated to be visualized through the molecular networking between the identical fragments $(\mathrm{m} / \mathrm{z})$ of definite metabolites. Through the network, each node was characterized with the parent mass $[\mathrm{M}-\mathrm{H}]^{-}$and the contiguous arrows (edges) connected between the similar nodes. The network was built for the negative ionization (-ve) mode using the GNPS 2 platform (Figure 2). The (-ve) network involved 148 nodes, 71 self-looped (individual) nodes, and 92 connected components. The designed networks facilitated the visual examination of the different compound families and analogues and assisted in isomer differentiation.

In the negative network, five clusters, A, B, C, D, and E, were mentioned and annotated as apigenin derivatives, which were grouped as methylated flavones, $\mathrm{O}$-glycosidic flavones, C-glycosidic flavones, and/or biflavones. In addition, the other self-looped nodes asterisked within the network were denoted as phenolic-O-glycosides, $\mathrm{N}$-acetylamino acid, flavan-3-ol, phenolic acids, and biflavones. 
Organic acids: Quinic acid was determined with an $[\mathrm{M}-\mathrm{H}]^{-}$ion at $m / z 191$ fragmented to $m / z 111$, and 173, whereas malic acid was characterized with an $[\mathrm{M}-\mathrm{H}]^{-}$ion at $m / z 133$ and fragmented to $m / z 115,89$, and 71. Phenolic acids: These structures were tentatively identified as eucomic acid, syringic acid-4-O- hexoside, sinapic acid 3-O-glucoside, and dihydrosinapic acid hexoside. They showed negative molecular ions at $m / z 239,359,375$, 385, and 387, respectively. These structures were tentatively identified depending on the main fragments that are shown in Table 1. Flavonoids and their glycosides: Most of the aglycones were found to be apigenin derivatives and their $O$ - and/or $C$-linkage of mono and/or diglycosides. The MS of C-glycosides was characterized through the main fragmentations by the loss of different masses of 60, 90, 120, and 240 Daltons [36]. A

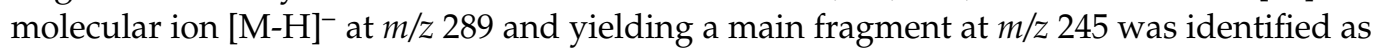
catechin. Biflavonoids: Several signals that gave parent ions $[\mathrm{M}-\mathrm{H}]^{-}$of $\mathrm{m} / \mathrm{z} 551,555,565$, 579,581 , and 609 were fragmented into specific fragments that characterized bioflavonoid derivatives [37]. Their identification, retention times, molecular weights, and fragmentation pattern are shown in Table 1.

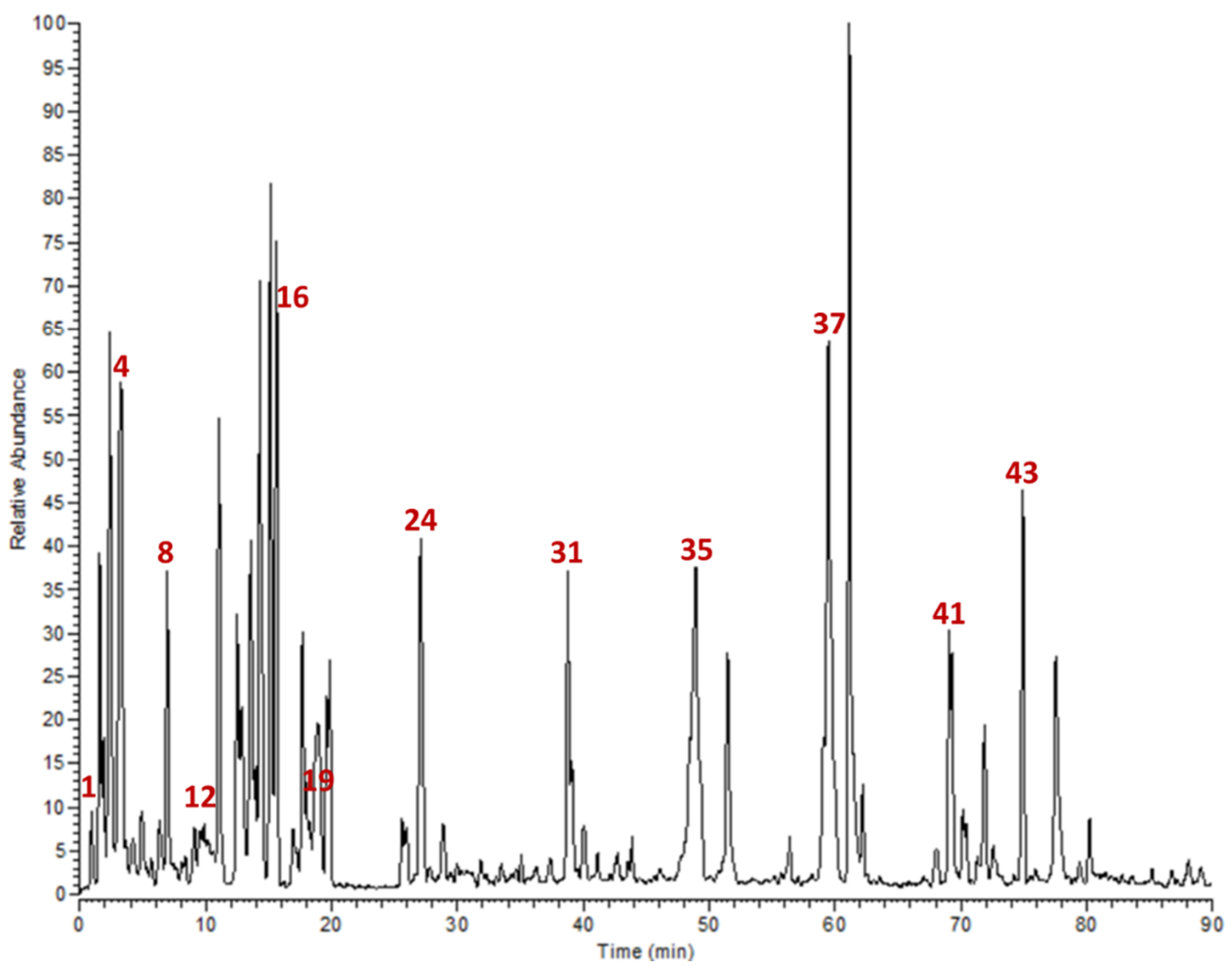

Figure 1. Base peak chromatogram of L. coronopifolia Poir. aerial parts' extract. 

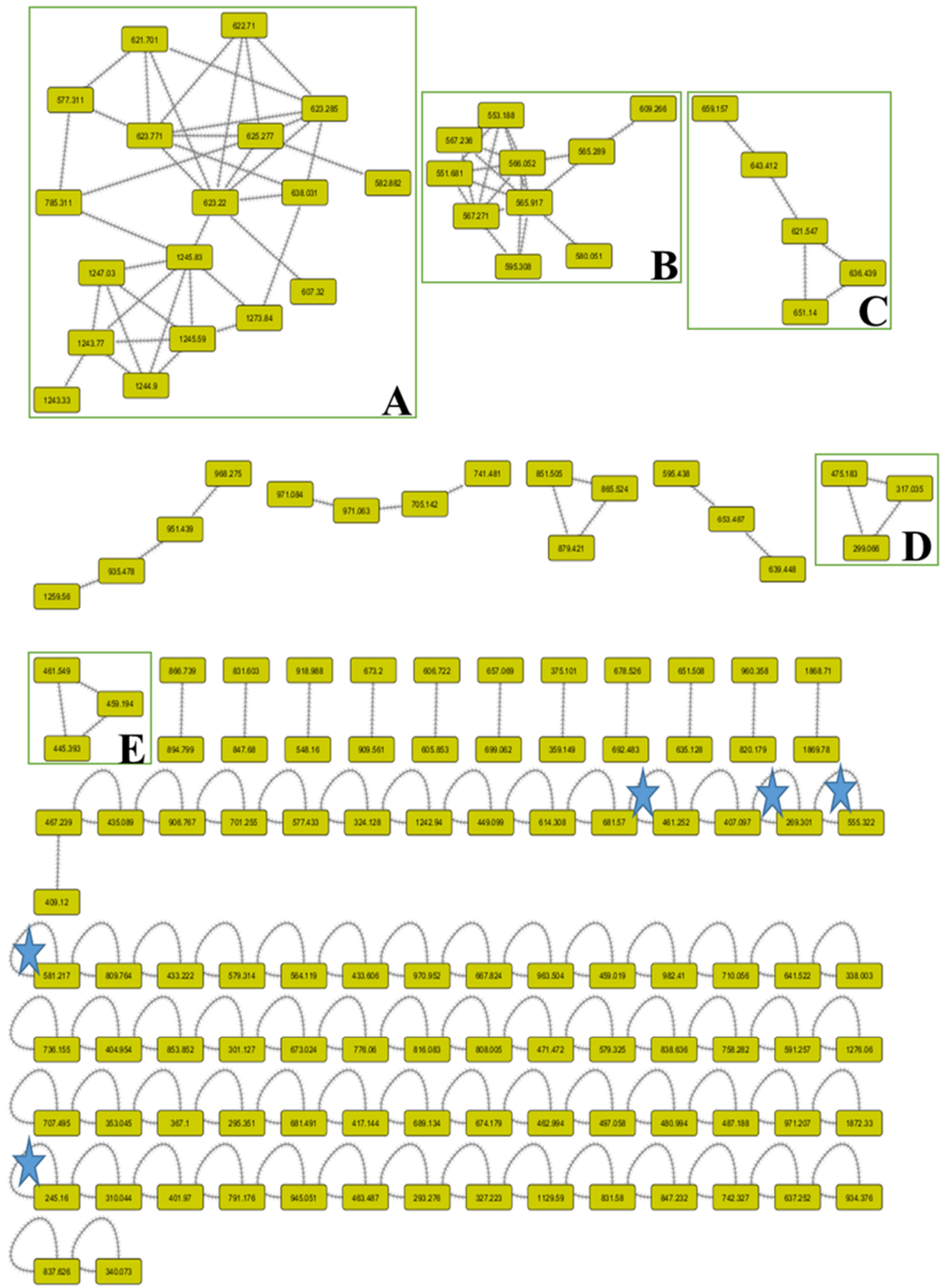

Figure 2. Complete molecular networking (MNW) generated using MS/MS data in (-ve) negative mode from L. coronopifolia aerial parts' extract. Nodes are labeled with parent mass. 
Table 1. Chemical composition of L. coronopifolia Poir. aerial parts' extract using LC-MS/MS.

\begin{tabular}{|c|c|c|c|c|c|}
\hline No. & $t_{\mathrm{R}}(\min )$ & {$[\mathbf{M}-\mathbf{H}]^{-}$} & $\operatorname{MS}^{2}(m / z)$ & Tentatively Identified Compound & Ref. \\
\hline 1 & 1.68 & 191 & 111,173 & Quinic acid ${ }^{a}$ & [38] \\
\hline 2 & 1.75 & 133 & $89,71,115$ & Malic acid ${ }^{a}$ & [39] \\
\hline 3 & 3.51 & 211 & 137,179 & Caffeic acid derivative ${ }^{b}$ & \\
\hline 4 & 4.03 & 239 & $149,179,221$ & Eucomic acid ${ }^{b}$ & \\
\hline 5 & 4.34 & 359 & $315,197,153$ & Syringic acid $4-O$-hexoside ${ }^{b}$ & [38] \\
\hline 6 & 4.61 & 237 & $115,121,137$ & 2-(4-hydroxybenzyl)-malic acid ${ }^{b}$ & \\
\hline 7 & 5.03 & 375 & $125,169,213$ & Sinapoyl trihydroxybenzoic acid ${ }^{b}$ & \\
\hline 8 & 6.31 & 475 & 197,359 & Rosmarinic acid malate $b$ & \\
\hline 9 & 7.78 & 461 & 153,315 & Protocatechuic acid rhamnosyl glucoside $b$ & \\
\hline 10 & 8.95 & 245 & $203,186,115$ & $N$-Acetyltryptophan C & \\
\hline 11 & 9.18 & 289 & 245 & Catechin $\mathrm{d}$ & {$[40]$} \\
\hline 12 & 9.29 & 299 & $115,133,183$ & Methyl trihydroxybenzoic acid malate ${ }^{b}$ & \\
\hline 13 & 13.54 & 385 & 223,179 & Sinapic acid 3-O-glucoside $\mathrm{e}^{\mathrm{C}}$ & \\
\hline 14 & 13.69 & 387 & $433,225,179$ & Dihydrosinapic acid hexoside $\mathrm{e}^{\mathrm{a}}$ & \\
\hline 15 & 14.51 & 387 & $433,225,179$ & Dihydrosinapic acid hexoside $\mathrm{e}^{\mathrm{T}}$ & \\
\hline 16 & 15.61 & 387 & $433,225,179$ & Dihydrosinapic acid hexoside ${ }^{\mathrm{e}}$ & \\
\hline 17 & 17.57 & 389 & 227 & Resveratrol glucoside $\mathrm{f}$ & \\
\hline 18 & 17.72 & 461 & 285 & Isoscutellarein-8-O-glucuronide ${ }^{\#, g}$ & \\
\hline 19 & 18.25 & 359 & $197,179,161,135$ & Rosmarinic acid ${ }^{\mathrm{b}}$ & \\
\hline 20 & 18.77 & 389 & 227 & Resveratrol glucoside $^{f}$ & \\
\hline 21 & 19.88 & 461 & 285 & Luteolin-7-O-hexouronide $\mathrm{g}$ & [6] \\
\hline 22 & 20.67 & 593 & $503,473,383,353$ & Apigenin di-C-hexoside $\mathrm{g}$ & [6] \\
\hline 23 & 25.79 & 445 & 269,175 & Apigenin-7-O-hexournide I ${ }^{\circledR, g}$ & {$[6]$} \\
\hline 24 & 27.05 & 445 & 269,175 & Apigenin-7-O-hexouronide II $\mathrm{g}$ & [6] \\
\hline 25 & 28.62 & 623 & $477,461,315$ & $\begin{array}{l}\text { Hypolaetin } 4^{\prime} \text {-O-methyl } \\
\text { ether-O-hexoside-O-rhamnoside I } \mathrm{g}\end{array}$ & \\
\hline 26 & 33.57 & 623 & $477,461,315$ & $\begin{array}{l}\text { Hypolaetin- } 4^{\prime} \text {-O-methyl } \\
\text { ether-O-hexoside- } O \text {-rhamnoside II g }\end{array}$ & \\
\hline 27 & 32.30 & 623 & $179,315,461$ & Isorhamnetin $O$-hexoside- $O$-rhamnoside $\mathrm{g}$ & \\
\hline 28 & 34.98 & 607 & $461,315,299$ & Hypolaetin di-O-rhamnoside $\mathrm{g}$ & \\
\hline 29 & 35.08 & 447 & 285 & Luteolin-7-O-glucoside ${ }^{\#, g}$ & {$[6]$} \\
\hline 30 & 37.23 & 637 & $491,461,315$ & $\begin{array}{l}\text { Hypolaetin } 4^{\prime}-O \text {-methyl } \\
\text { ether-8-glucuronide-O-rhamnoside } \mathrm{g}\end{array}$ & \\
\hline 31 & 38.80 & 459 & 283,268 & Acacetin- $O$-hexouronic acid $\mathrm{g}$ & {$[41]$} \\
\hline 32 & 41.04 & 577 & 269 & Apigenin-O-caffeoyl rhamnoside $\mathrm{g}$ & \\
\hline 33 & 41.14 & 461 & 299,283 & Methoxy leteolin-7-O-hexoside $\mathrm{g}$ & \\
\hline 34 & 43.90 & 651 & $505,475,329$ & Tricin-O-feruloyl rhamnoside $\mathrm{g}$ & \\
\hline 35 & 48.62 & 621 & 459,313 & Crismaritin-O-caffeoyl rhamnoside $^{g}$ & \\
\hline 36 & 51.41 & 327 & $171,229,327$ & Unknown & \\
\hline 37 & 59.10 & 313 & $298,284,269$ & Luteolin-7,3'-dimethyl ether $\mathrm{g}$ & {$[6]$} \\
\hline 38 & 61.18 & 269 & $269,151,149$ & Apigenin $\mathrm{g}$ & [6] \\
\hline 39 & 62.63 & 555 & $403,429,327,299$ & Binaringenin methyl ether ${ }^{h}$ & [37] \\
\hline 40 & 69.07 & 551 & $457,431,389$ & Methoxy amentoflavone $\mathrm{h}$ & \\
\hline 41 & 69.42 & 553 & $458,432,390$ & Dihydrobilobetin $^{\mathrm{h}}$ & \\
\hline 42 & 71.92 & 283 & 268,133 & Acacetin $\mathrm{g}$ & {$[41]$} \\
\hline 43 & 75.90 & 565 & 471,389 & Dimethoxy amentoflavone ${ }^{h}$ & \\
\hline 44 & 78.77 & 609 & $577,551,489,269$ & Penta methoxy dihydro biapigenin $\mathrm{h}$ & \\
\hline 45 & 81.37 & 579 & $533,485,389,268$ & Kayaflavone ${ }^{\mathrm{h}}$ & \\
\hline 46 & 81.81 & 581 & $579,535,487$ & Dihydrokayaflavone $\mathrm{h}$ & \\
\hline
\end{tabular}

\# Isolated before from the same species [4]. ${ }^{\circledR}$ Confirmed by UV $\lambda_{\max } \cdot{ }^{a}$ Organic acid, ${ }^{\mathrm{b}}$ phenolic acid, ${ }^{\mathrm{c}}$ amino acid derivative, ${ }^{\mathrm{d}}$ flavan-3-ol, ${ }^{\mathrm{e}}$ phenylpropanoic acid, ${ }^{\mathrm{f}}$ stilbenoid, ${ }^{\mathrm{g}}$ flavone, and ${ }^{\mathrm{h}}$ biflavonoid.

\section{3. ${ }^{1} \mathrm{H}-\mathrm{NMR}$ Analysis of L. coronopifolia Extract}

The extract was dissolved in deuterated dimethyl sulfoxide (DMSO-d6) and introduced into the proton NMR (500 MHz) experiment. The resonated peaks at different chemical shifts explained the kind of protons present in the chemical structures and repre- 
sented the classes of skeletons in the solution. The 2-phenyl chromen-4-one of the flavone structure bearing substituents at positions 5 and 7 of A-ring was observed as the main skeleton. Through the ${ }^{1} \mathrm{HNMR}$ chart, the downfield protons that appeared as a doublet at $\delta 7.93 \mathrm{ppm}$ were characterized for $\mathrm{H}-2^{\prime}$ and $6^{\prime}$ of B-ring, while the protons resonating at $\delta 6.92 \mathrm{ppm}$ were assigned for $\mathrm{H}-3^{\prime}$ and $5^{\prime}$ of B-ring, with the ortho-coupling constant $\left(J=9.0 \mathrm{~Hz}\right.$ ) suggesting that the B-ring bearing the hydroxyl group was at position $4^{\prime}$, while the appearance of a singlet proton at $\delta 6.83$ ppm was characterized for $\mathrm{H}-3$ of the flavone structure. In addition, the downfield shift observed at $\delta 6.42$ and $6.81 \mathrm{ppm}$ for H- 6 and $\mathrm{H}-8$ of the A-ring of the flavone structure with meta-coupling $(2 \mathrm{~Hz})$ or broad singlet was predicted due to the substitution at position 7 . The previous interpretation confirmed the presence of the apigenin derivative in the solution with substitution at position 7 . In addition, the $\mathrm{ABX}$ system of B-ring was observed along with the chart through the coupling constant of resonated protons as a doublet of doublet (ortho- and meta-coupled), doublet (meta-coupled), and doublet (ortho-coupled) at $\delta 7.46,7.43$, and $6.92 \mathrm{ppm}$, respectively, were assigned, respectively, for $\mathrm{H}-6^{\prime}, \mathrm{H}-2^{\prime}$, and $\mathrm{H}-5^{\prime}$ of the B-ring, suggesting that the B-ring was substituted with substituents at positions $3^{\prime}$ and $4^{\prime}$. The rest of $\mathrm{H}-3, \mathrm{H}-6$, and $\mathrm{H}-8$ proton signals resonated around the mentioned chemical shifts, which confirmed the presence of a luteolin derivative with 7-O-substituents. In addition, the resonated singlet signal at $\delta$ of 3.83 ppm was assigned to 4'-O-methylated flavone (i.e., the presence of an acacetin or methyl apigenin derivative in the solution). Moreover, the series of signals between $\delta 3.14$ and 3.51 ppm were attributable to a sugar moiety, and the doublet signal with a coupling constant of $7.2 \mathrm{~Hz}$ was distinctive for the anomeric proton of sugar with $\mathrm{O}-\beta$-D-linkage. Depending on the previously published data and MS assignment, the major attached sugar for the flavone structure is glucuronide moiety.

\subsection{Insecticidal Activity}

Plant extracts are considered a new ecofriendly and efficient alternative means for controlling mosquitoes. The larvicidal activity of the extract was evaluated against the 3rd instar larvae of $C$. pipiens. The fiducial limits were calculated for $\mathrm{LC}_{25}, \mathrm{LC}_{50}$, and $\mathrm{LC}_{95}$ at $p<0.05$ (Table 2). The extract exhibited considerable larvicidal activity against C. pipiens larvae where the $\mathrm{LC}_{50}$ values after 24,48 , and $72 \mathrm{~h}$ of exposure were $52.74,34.07$, and $29.076 \mu \mathrm{g} / \mathrm{mL}$, respectively. The essential oil from the Egyptian plants exhibited insecticidal activity against the 4 th larval instar of $C$. pipiens [42]. Similar activities were reported from essential oils of other Lavandula species, among them L. stoechas and L. dentata $[43,44]$.

Table 2. Larvicidal activity of L. coronopifolia extract against the 3rd instar larvae of Culex pipiens 24, 48 , and $72 \mathrm{~h}$ post treatment.

\begin{tabular}{|c|c|c|c|}
\hline Extract $(\mu \mathrm{g} / \mathrm{mL})$ & 24 h Post Treatment & $48 \mathrm{~h}$ Post Treatment & $72 \mathrm{~h}$ Post Treatment \\
\hline $\mathrm{LC}_{25}\left({ }^{*}\right.$ F.1. at $\left.95 \%\right)$ & $20.054(15.20-24.85)$ & $11.274(7.55-15.05)$ & 8.668 (5.29-12.21) \\
\hline $\mathrm{LC}_{50}\left({ }^{*}\right.$ F.1. at $\left.95 \%\right)$ & $52.74(44.304-62.95)$ & $34.07(27.43-41.41)$ & $29.076(22.58-36.062)$ \\
\hline $\mathrm{LC}_{95}\left({ }^{*}\right.$ F.1. at $\left.95 \%\right)$ & $557.50(374.11-975.18)$ & $\begin{array}{c}505.44 \\
(326.011-953.94)\end{array}$ & $\begin{array}{c}556.28 \\
(341.87-1151.47)\end{array}$ \\
\hline Slope \pm SE & $1.61 \pm 0.147$ & $1.40 \pm 0.141$ & $1.28 \pm 0.138$ \\
\hline$\chi^{2 \mathrm{a}}$ & 6.4544 & 1.9897 & 0.5856 \\
\hline Probability $(\mathrm{P})$ & 0.0915 & 0.5745 & 0.8997 \\
\hline
\end{tabular}

\subsection{Biochemical Activity}

Insects release several detoxifying enzymes such as esterases, oxidases, and reductases to face and detoxify many invader pesticides [45]. To get an insight into the mechanisms involved, we explored the activities of five different enzymes in the 3rd larval instar of C. pipiens. The extract, at a concentration of $\mathrm{LC}_{50}$ and exposure time of $72 \mathrm{~h}$, inhibited cytochrome P-450 monooxygenase, acetylcholinesterase, and carboxylesterase by $-9.92 \%$, $-19.41 \%$, and $-25.47 \%$, respectively, compared to the control group (Figure 3 ), while the 
treated larvae showed elevation of $\alpha$-esterases and glutathione S-transferase contents by $15.63 \%$ and $37.02 \%$ compared to the untreated larvae. This could highlight the significant role of glutathione S-transferase and $\alpha$-esterases in the detoxification mechanism of the extract. Our results come in agreement with those of the Huang et al. study, which reported an increase in the intracellular glutathione content when the larvae were treated with a polyphenolic-rich extract [46-48].

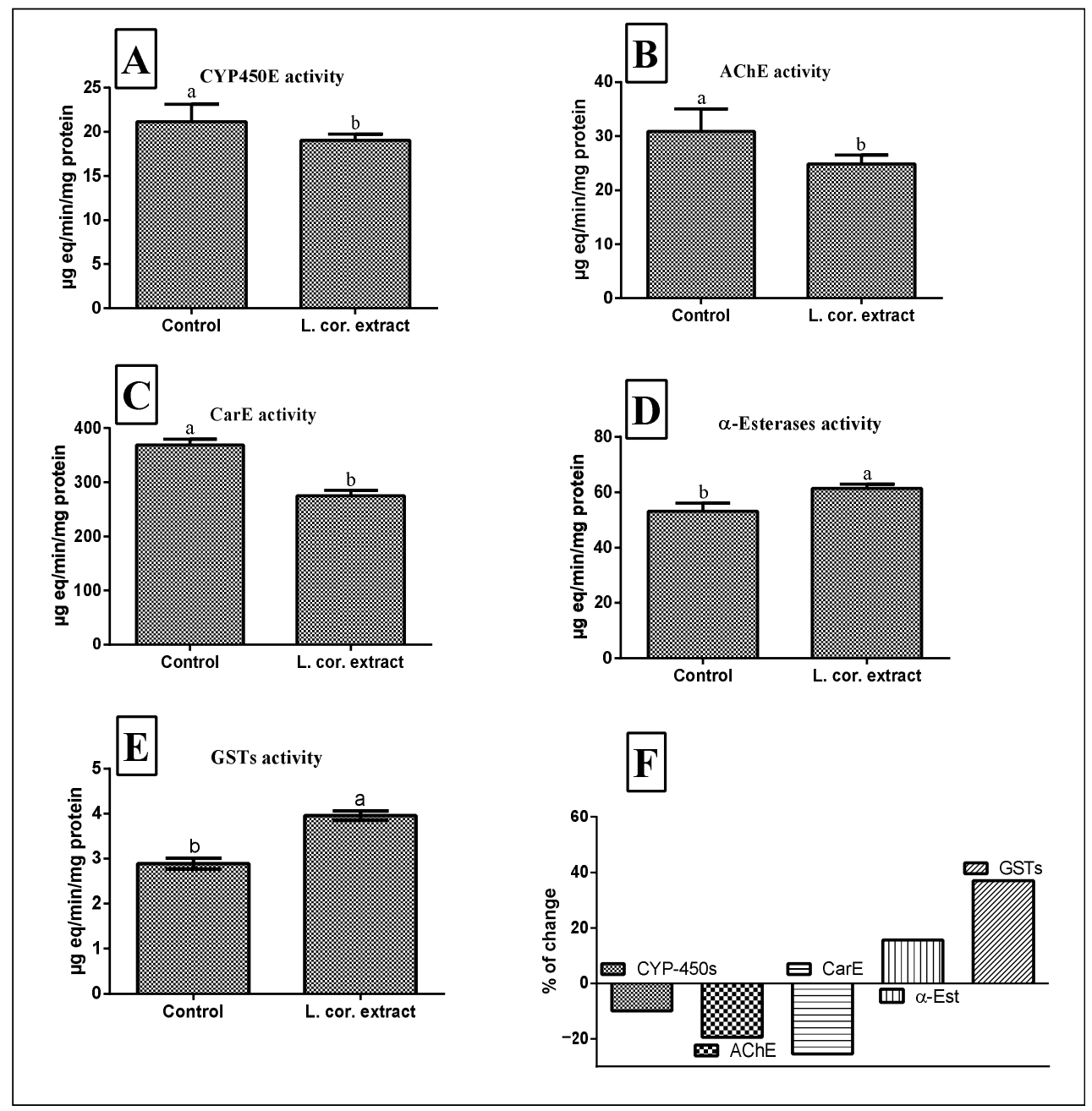

Figure 3. Effects of L. coronopifolia extract (L. cor.) on the enzymatic activities of cytochrome P-450 monooxygenase (CYP-450s) (A), carboxylesterase (CarE) (B), acetylcholinesterase (AchE) (C), $\alpha$-esterases (D), and glutathione S-transferase (GSTs) (E) in the 3rd larval instar of C. Pipiens. (F); \% of changes. Data were represented as mean \pm SE. Lowercase letters above the bars indicate significant differences between different treatment groups (Duncan's multiple range test, $p<0.01$ ). Error bars indicate $95 \%$ confidence intervals.

As the time of exposure increased, the toxicity of the extract to the 3rd instar larvae increased, followed by a substantial decrease in carboxylesterase (CarE), acetylcholinesterase (AChE), and cytochrome P-450 monooxygenase (CYP450) levels. This suggests the temporary response and neurotoxic effects of the extract. Our results come in agreement with those of the Gershenzon et al. and Salunke et al. studies, which reported the inhibitory effect of natural secondary metabolites for the detoxification enzymes mentioned previously [49-53]. 


\subsection{Microbiological Studies}

3.6.1. Antimicrobial Susceptibility, MIC, and MBC

The antimicrobial susceptibility screening was performed by the cup diffusion method. The results showed that all tested P. aeruginosa were susceptible to the extract compared to the anti-pseudomonal activity of ciprofloxacin $(2 \mathrm{mg} / \mathrm{mL}$; Table 3$)$. The extract displayed moderate activities against all the clinical isolates of P. aeruginosa and P. aeruginosa ATCC (12924) in the microdilution test (Table 3).

Table 3. Antimicrobial susceptibility, minimum inhibitory concentration (MIC), and minimal bactericidal concentration $(\mathrm{MBC})$ of the L. coronopifolia extract and ciprofloxacin against the tested P. aeruginosa.

\begin{tabular}{ccccc}
\hline \multirow{2}{*}{$\begin{array}{c}\text { P. aeruginosa } \\
\text { Isolates }\end{array}$} & \multicolumn{2}{c}{ Zone of Inhibition $(\mathbf{m m})$} & \multicolumn{2}{c}{ Extract } \\
\cline { 2 - 5 } & Extract & Ciprofloxacin & MIC & MBC \\
\cline { 3 - 5 } & & & \multicolumn{2}{c}{$\mathbf{~ m g / m L}$} \\
\hline C1 & 20 & 1748 & 0.3125 & 1.25 \\
C2 & 20 & 40 & 0.3125 & 1.25 \\
C3 & 20 & 50 & 0.3125 & 1.25 \\
C4 & 28 & 35 & 0.3125 & 1.25 \\
ATCC $(12924)$ & 26 & 22 & 0.1562 & 1.25 \\
\hline
\end{tabular}

\subsubsection{Biofilm Formation and Quantification Assay}

Twenty clinical isolates of Pseudomonas were examined for their ability to form a biofilm using the microtiter plate method. Out of the tested isolates, four bacteria showed biofilm formation, where the clinical isolate $\mathrm{C} 4$ exhibited the strongest biofilm formation, while C1, C2, C3, and P. aeruginosa ATCC (12924) showed moderate biofilm formation (Figure 4).

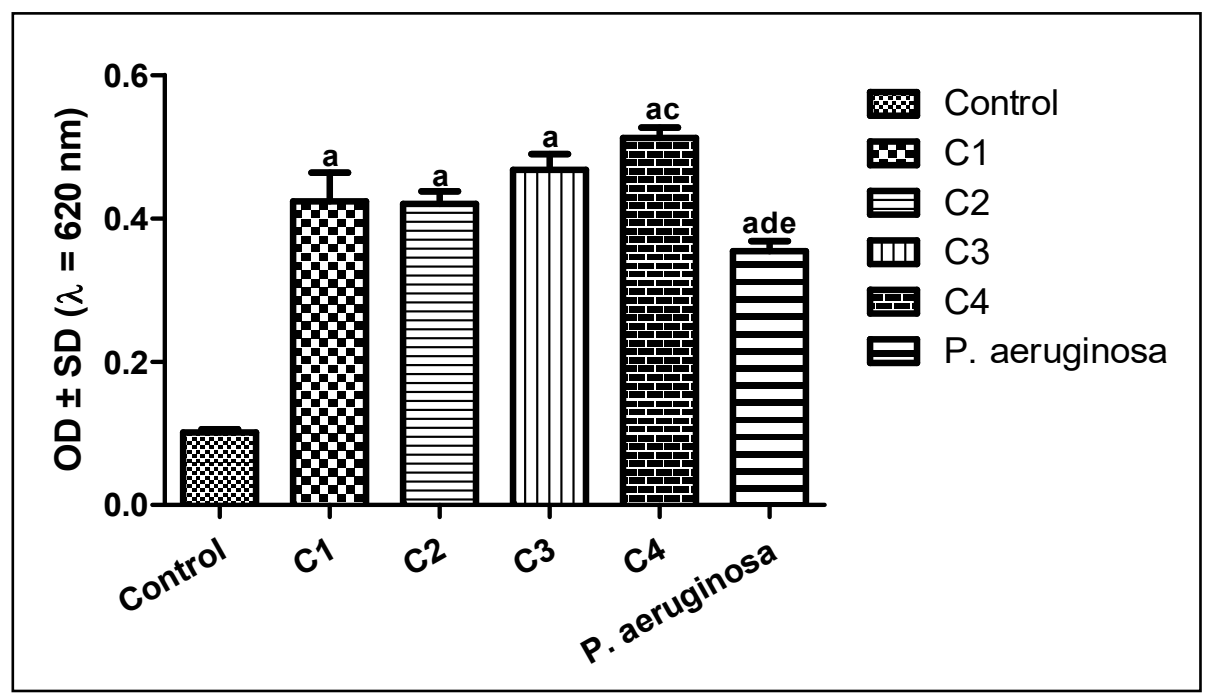

Figure 4. Results of biofilm formation of $P$. aeruginosa. Isolates were classified as negative (OD $\leq \mathrm{ODc})$, weak (ODc $\leq \mathrm{OD} \leq 2 \mathrm{ODc})$, moderate (2ODc $<\mathrm{OD} \leq 4 \mathrm{ODc})$, and strong biofilm production (4ODc $<\mathrm{OD}) . \mathrm{OD}=$ optical density. ${ }^{a}$ Significant compared to control at $p<0.05$. ${ }^{\mathrm{b}}$ Significant compared to $\mathrm{C} 1$ at $p<0.05$. ${ }^{\mathrm{c}}$ Significant compared to $\mathrm{C} 2$ at $p<0.05$. ${ }^{\mathrm{d}}$ Significant compared to C3 at

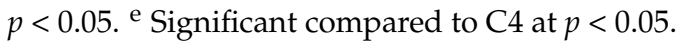




\subsubsection{Biofilm Inhibition Assay}

The biofilm inhibition activity of the extract was evaluated using three concentrations $(1 / 2,1 / 4,1 / 8 \mathrm{MICs})$. The extract inhibited the biofilm formation of P. aeruginosa in a dosedependent manner and ranged from 17 to $38 \%$ (Figure 5). These considerable antibiofilm properties are similar to that of polyphenol-rich extract from the bark of Salix tetrasperma and the leaves of Annona glabra and Gynura procumbens [54-56]. A recent study by Koely et al. described the antibiofilm activities of Enydra fluctuans against P. aeruginosa. They also attributed these activities to the presence of several bioactive phenolic compounds, among them kaempferol, quercetin, and luteolin and their glycosides [57]. In addition, different crude extracts from Arbutus unedo having high phenolic contents demonstrated comparable antibacterial activity [58].

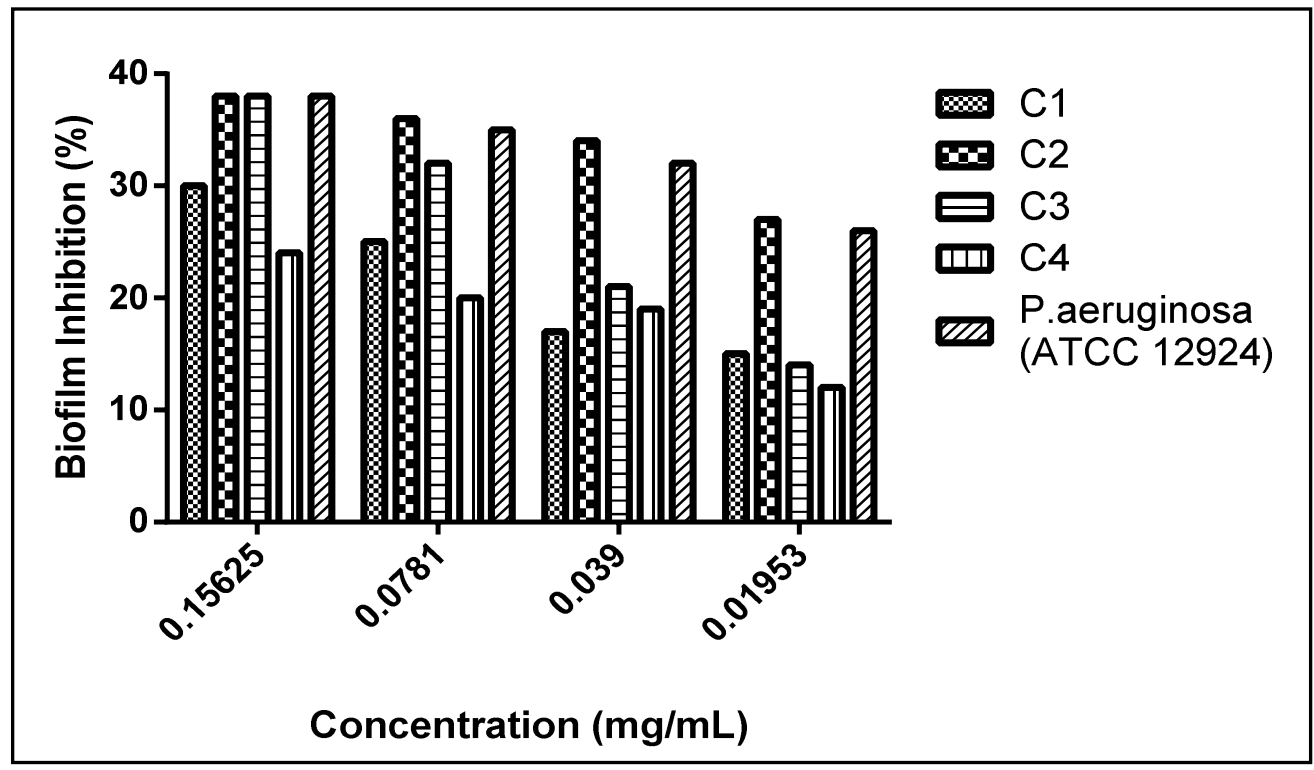

Figure 5. Biofilm formation inhibition activities of L. coronopifolia extract against P. aeruginosa isolates.

\subsubsection{Synergistic Activities}

Antimicrobial resistance (AMR) has increased markedly in the recent years and is causing a major threat to patients' treatment. P. aeruginosa, for example, has developed antibiotic resistance, and its increasing dissemination is causing severe infections in hospitals. Combinations of plant extracts with antibiotics represent a novel approach to increase their effectiveness and to overcome AMR. In an attempt to explore the synergistic activities of the extract, we combined it with the reference drug ciprofloxacin in a 1:1 ratio. The combination of ciprofloxacin and the extract substantially potentiated the reduction of biofilm from $24 \%, 20 \%$, and $19 \%$ to $53.5 \%, 48.9 \%$, and $45.26 \%$ at $1 / 2,1 / 4$, and $1 / 8 \mathrm{MICs}$, respectively (Figure 6). Our findings come in agreement with those of Okansi et al. (2013), who reported a synergy when ciprofloxacin was combined with the methanol extract of Phyllantus muellerianus leaves (containing flavonoids) against $P$. aeruginosa [59]. Another study described the synergistic activities against $P$. aeruginos $a$ when zingerone extract was combined with the reference drug ciprofloxacin [60].

Coronavirus disease 2019 (COVID-19) has become the utmost and worst public health crisis of our generation. There are several risk factors associated with COVID-19, among them secondary bacterial infections, which in turn lead to serious negative outcomes and fatal clinical complications. To prevent these negative outcomes and secondary bacterial infections, patients with serious illness are treated with antibiotics. As a result, the use of antibiotics has increased, and this will significantly elevate the antibiotic resistance rates [61]. Plant extracts, with diverse secondary metabolites and several molecular targets, alone or as an adjuvant therapy, would not only boost the overall antimicrobial properties 
but can also work as modifying/modulating agents. This will effectively reduce the use of antibiotics and, therefore, reduce the risk of developing antibiotic resistance [62].

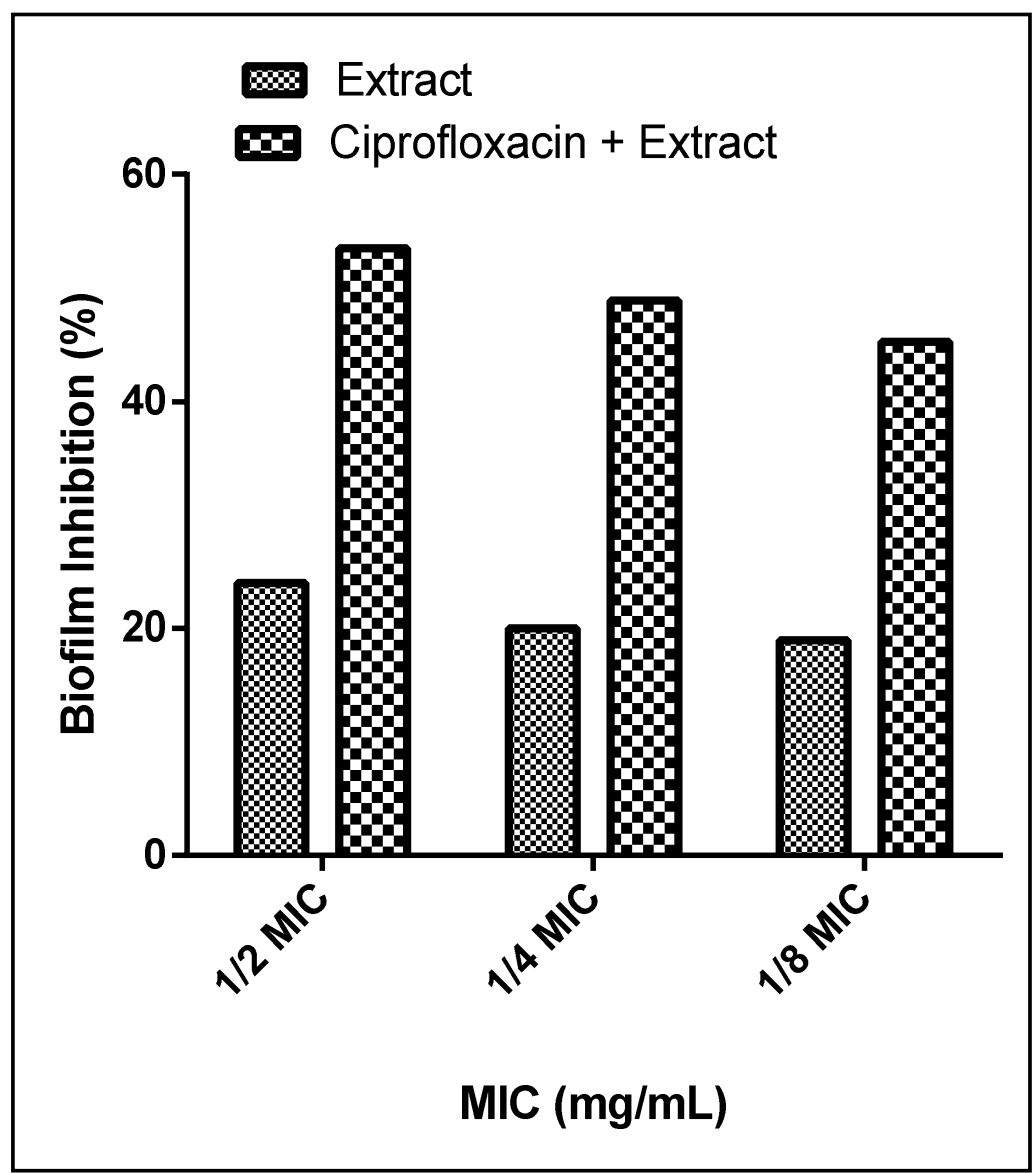

Figure 6. Biofilm formation activity of L. coronopifolia extract alone and in combination with ciprofloxacin on C4 isolate.

\section{Conclusions}

In this study, the LC-MS profiling of L. coronopifolia extract revealed 46 secondary metabolites. The extract displayed promising insecticidal activities against 3rd instar larvae of $C$. pipiens. The larvae showed a defensive mechanism by increasing the activities of detoxification enzymes of GSTs and $\alpha$-esterases, while the toxification of C. pipiens was significantly observed through the reduction of CarE, AChE, and CYP450 activities. Moreover, the extract demonstrated promising antibiofilm formation against $P$. aeruginosa alone and when combined with the reference drug ciprofloxacin. To sum up, the wild plant, L. coronopifolia, exploits a substantial natural source to control disease carriers and manage resistant bacteria infections. Further studies are needed to evaluate the effects of L. coronopifolia extract on the life cycle of $C$. pipiens larvae and to explain the regulatory mechanisms of toxification.

Author Contributions: Conceptualization, M.E., M.M.S., R.R.A.L., M.A.E.R., M.S., L.J.M.A.-H., D.R.A.-H. and S.M.F.; formal analysis, M.E., D.R.A.-H., L.J.M.A.-H., M.S. and M.A.E.R.; methodology, M.E., D.R.A.-H., M.M.S., L.J.M.A.-H., R.R.A.L., S.M.F., M.S. and M.A.E.R.; validation, D.R.A.-H., L.J.M.A.-H., M.E., and M.S.; visualization, M.E., and M.S.; Writing-original draft, M.E., D.R.A.-H., M.M.S., L.J.M.A.-H., R.R.A.L., S.M.F. and M.A.E.R.; Writing-review and editing, M.S. and M.E. All authors have read and agreed to the published version of the manuscript.

Funding: This research did not receive any specific grant from funding agencies in the public, commercial, or not-for-profit sectors. 
Institutional Review Board Statement: Not applicable.

Informed Consent Statement: Not applicable.

Data Availability Statement: All data are included at the manuscript.

Conflicts of Interest: There is no conflict of interest.

Sample Availability: Samples of the extract are available from the authors.

\section{References}

1. Raju, P.; Arivalagan, P.; Natarajan, S. One-pot fabrication of multifunctional catechin@ ZIF-L nanocomposite: Assessment of antibiofilm, larvicidal and photocatalytic activities. J. Photochem. Photobiol. B Biol. 2020, 203, 111774. [CrossRef] [PubMed]

2. Bagavan, A.; Rahuman, A.A. Evaluation of larvicidal activity of medicinal plant extracts against three mosquito vectors. Asian Pac. J. Trop. Med. 2011, 4, 29-34. [CrossRef]

3. Angajala, G.; Ramya, R.; Subashini, R. In-vitro anti-inflammatory and mosquito larvicidal efficacy of nickel nanoparticles phytofabricated from aqueous leaf extracts of Aegle marmelos Correa. Acta Trop. 2014, 135, 19-26. [CrossRef] [PubMed]

4. El-Garf, I.; Grayer, R.J.; Kite, G.C.; Veitch, N.C. Hypolaetin 8-O-glucuronide and related flavonoids from Lavandula coronopifolia and L. pubescens. Biochem. Syst. Ecol. 1999, 27, 843-846. [CrossRef]

5. The Plant List (2013). Version 1.1. Available online: http://www.theplantlist.org/ (accessed on 1 January 2021).

6. Contreras, M.D.; Algieri, F.; Rodriguez-Nogales, A.; Gálvez, J.; Segura-Carretero, A. Phytochemical profiling of anti-inflammatory Lavandula extracts via RP-HPLC-DAD-QTOF-MS and-MS/MS: Assessment of their qualitative and quantitative differences. Electrophoresis 2018, 39, 1284-1293. [CrossRef] [PubMed]

7. Harborne, J.B.; Williams, C.A. Phytochemistry of the Genus Lavandula; CRC Press: London, UK, 2002.

8. Lis-Balchin, M. Lavender: The Genus Lavandula; CRC Press: Boca Raton, FL, USA, 2002.

9. El-Gendi, O.D.; Kusano, A.; Kusano, G. Two new triterpenic glucosidates from Lavandula coronipifolia in Egypt. Nat. Med. 2000, $54,38-41$.

10. Elsbaey, M.; Mwakalukwa, R.; Shimizu, K.; Miyamoto, T. Pentacylic triterpenes from Lavandula coronopifolia: Structure related inhibitory activity on $\alpha$-glucosidase. Nat. Prod. Res. 2019, 1-9. [CrossRef] [PubMed]

11. Messaoud, C.; Chograni, H.; Boussaid, M. Chemical composition and antioxidant activities of essential oils and methanol extracts of three wild Lavandula L. species. Nat. Prod. Res. 2012, 26, 1976-1984. [CrossRef]

12. Hassan, W.; El Gamal, A.; El-Sheddy, E.; Al-Oquil, M.; Farshori, N. The chemical composition and antimicrobial activity of the essential oil of Lavandula coronopifolia growing in Saudi Arabia. J. Chem. Pharm. Res. 2014, 6, 604-615.

13. Farshori, N.N.; Al-Sheddi, E.S.; Al-Oqail, M.M.; Hassan, W.H.; Al-Khedhairy, A.A.; Musarrat, J.; Siddiqui, M.A. Hepatoprotective potential of Lavandula coronopifolia extracts against ethanol induced oxidative stress-mediated cytotoxicity in HepG2 cells. Toxicol. Ind. Health 2015, 31, 727-737. [CrossRef]

14. Ait Said, L.; Zahlane, K.; Ghalbane, I.; El Messoussi, S.; Romane, A.; Cavaleiro, C.; Salgueiro, L. Chemical composition and antibacterial activity of Lavandula coronopifolia essential oil against antibiotic-resistant bacteria. Nat. Prod. Res. 2015, $29,582-585$. [CrossRef]

15. El-mekkawy, S.; Shahat, A.A.; Alqahtani, A.S.; Alsaid, M.S.; Abdelfattah, M.A.; Ullah, R.; Emam, M.; Yasri, A.; Sobeh, M. A Polyphenols-Rich Extract from Moricandia sinaica Boiss. Exhibits Analgesic, Anti-Inflammatory and Antipyretic Activities In Vivo. Molecules 2020, 25, 5049. [CrossRef] [PubMed]

16. El-Garawani, I.; Emam, M.; Elkhateeb, W.; El-Seedi, H.; Khalifa, S.; Oshiba, S.; Abou-Ghanima, S.; Daba, G. In Vitro Antigenotoxic, Antihelminthic and Antioxidant Potentials Based on the Extracted Metabolites from Lichen, Candelariella vitellina. Pharmaceutics 2020, 12, 477. [CrossRef] [PubMed]

17. El Raey, M.A.; El-Hagrassi, A.M.; Osman, A.F.; Darwish, K.M.; Emam, M. Acalypha wilkesiana flowers: Phenolic profiling, cytotoxic activity of their biosynthesized silver nanoparticles and molecular docking study for its constituents as Topoisomerase-I inhibitors. Biocatal. Agric. Biotechnol. 2019, 20, 101243. [CrossRef]

18. Wang, M.; Carver, J.J.; Phelan, V.V.; Sanchez, L.M.; Garg, N.; Peng, Y.; Nguyen, D.D.; Watrous, J.; Kapono, C.A.; Luzzatto-Knaan, T. Sharing and community curation of mass spectrometry data with Global Natural Products Social Molecular Networking. Nat. Biotechnol. 2016, 34, 828-837. [CrossRef] [PubMed]

19. Gerberg, E.J.; Barnard, D.R.; Ward, R.A. Manual for Mosquito Rearing and Experimental Techniques; American Mosquito Control Association Inc.: Mount Laurel, NJ, USA, 1994.

20. World Health Organization. Guidelines for Laboratory and Field Testing of Mosquito Larvicides; World Health Organization: Geneva, Switzerland, 2005.

21. Amin, T. Biochemical and Physiological Studies of Some Insect Growth Regulators on the Cotton Leafworm Spodoptera littoralis (Boisd.). Ph.D. Thesis, Faculty of Science, Cairo University, Giza, Egypt, 1998.

22. Simpson, D.; Bull, D.; Lindquist, D. A semimicrotechnique for the estimation of cholinesterase activity in boll weevils. Ann. Entomol. Soc. Am. 1964, 57, 367-371. [CrossRef]

23. Van Asperen, K. A study of housefly esterases by means of a sensitive colorimetric method. J. Insect Physiol. 1962, 8, 401-414. [CrossRef] 
24. Habig, W.H.; Pabst, M.J.; Jakoby, W.B. Glutathione S-transferases the first enzymatic step in mercapturic acid formation. J. Biol. Chem. 1974, 249, 7130-7139. [CrossRef]

25. Hansen, L.; Hodgson, E. Biochemical characteristics of insect microsomes: N-and O-demethylation. Biochem. Pharmacol. 1971, 20, 1569-1578. [CrossRef]

26. El-Sayed, N.R.; Samir, R.; Abdel-Hafez, J.M.; Ramadan, M.A. Olive Leaf Extract Modulates Quorum Sensing Genes and Biofilm Formation in Multi-Drug Resistant Pseudomonas aeruginosa. Antibiotics 2020, 9, 526. [CrossRef]

27. Cooper, K. Theory of antibiotic inhibition zones in agar media. Nature 1955, 176, 510-511. [CrossRef]

28. Moideen, M.M.J.; Raffick, M.M. Antibacterial, antifungal activity and phytochemical analysis of Sanseviveria roxburghiana root. IJ Phytopharm. 2012, 3, 21-26.

29. Briceland, L.L.; Pasko, M.; Mylotte, J. Serum bactericidal rate as measure of antibiotic interactions. Antimicrob. Agents Chemother. 1987, 31, 679-685. [CrossRef] [PubMed]

30. Wikler, M.A. Methods for dilution antimicrobial susceptibility tests for bacteria that grow aerobically: Approved standard. CLSI (NCCLS) 2006, 26, M7-A7.

31. O'Toole, G.A.; Kolter, R. Initiation of biofilm formation in Pseudomonas fluorescens WCS365 proceeds via multiple, convergent signalling pathways: A genetic analysis. Mol. Microbiol. 1998, 28, 449-461. [CrossRef]

32. O'Toole, G.A. Microtiter dish biofilm formation assay. J. Vis. Exp. 2011, 47, e2437. [CrossRef] [PubMed]

33. Stepanović, S.; Vuković, D.; Hola, V.; Bonaventura, G.D.; Djukić, S.; Ćirković, I.; Ruzicka, F. Quantification of biofilm in microtiter plates: Overview of testing conditions and practical recommendations for assessment of biofilm production by staphylococci. Apmis 2007, 115, 891-899. [CrossRef]

34. Stepanović, S.; Vuković, D.; Dakić, I.; Savić, B.; Švabić-Vlahović, M. A modified microtiter-plate test for quantification of staphylococcal biofilm formation. J. Microbiol. Methods 2000, 40, 175-179. [CrossRef]

35. Duncan, D.B. Multiple range and multiple F tests. Biometrics 1955, 11, 1-42. [CrossRef]

36. Vukics, V.; Guttman, A. Structural characterization of flavonoid glycosides by multi-stage mass spectrometry. Mass Spectrom. Rev. 2010, 29, 1-16. [CrossRef] [PubMed]

37. Yao, H.; Chen, B.; Zhang, Y.; Ou, H.; Li, Y.; Li, S.; Shi, P.; Lin, X. Analysis of the total biflavonoids extract from Selaginella doederleinii by HPLC-QTOF-MS and its in vitro and in vivo anticancer effects. Molecules 2017, 22, 325. [CrossRef] [PubMed]

38. Sun, L.; Tao, S.; Zhang, S. Characterization and quantification of polyphenols and triterpenoids in thinned young fruits of ten pear varieties by UPLC-Q TRAP-MS/MS. Molecules 2019, 24, 159. [CrossRef]

39. Spínola, V.; Pinto, J.; Castilho, P.C. Identification and quantification of phenolic compounds of selected fruits from Madeira Island by HPLC-DAD-ESI-MSn and screening for their antioxidant activity. Food Chem. 2015, 173, 14-30. [CrossRef]

40. Yuzuak, S.; Ballington, J.; Xie, D.-Y. HPLC-qTOF-MS/MS-based profiling of flavan-3-ols and dimeric proanthocyanidins in berries of two muscadine grape hybrids FLH 13-11 and FLH 17-66. Metabolites 2018, 8, 57. [CrossRef]

41. Li, Q.; Wang, L.; Dai, P.; Zeng, X.; Qi, X.; Zhu, L.; Yan, T.; Wang, Y.; Lu, L.; Hu, M. A combined strategy of mass fragmentation, post-column cobalt complexation and shift in ultraviolet absorption spectra to determine the uridine $5^{\prime}$-diphosphoglucuronosyltransferase metabolism profiling of flavones after oral administration of a flavone mixture in rats. J. Chromatogr. A 2015, 1395, 116-128. [PubMed]

42. Helmy, N.; Bakr, R.F.; Nawwar, G.A.; Helmy, O.M. Biochemical effects of some agricultural waste extracts against Culex pipiens (Diptera: Culicidae). Egypt. Acad. J. Biol. Sci. C Physiol. Mol. Biol. 2010, 2, 75-81. [CrossRef]

43. Dris, D.; Tine-Djebbar, F.; Soltani, N. Lavandula dentata essential oils: Chemical composition and larvicidal activity against Culiseta longiareolata and Culex pipiens (Diptera: Culicidae). Afr. Entomol. 2017, 25, 387-394. [CrossRef]

44. Traboulsi, A.F.; Taoubi, K.; El-Haj, S.; Bessiere, J.M.; Rammal, S. Insecticidal properties of essential plant oils against the mosquito Culex pipiens molestus (Diptera: Culicidae). Pest Manag. Sci. 2002, 58, 491-495. [CrossRef]

45. Waliwitiya, R.; Nicholson, R.A.; Kennedy, C.J.; Lowenberger, C.A. The synergistic effects of insecticidal essential oils and piperonyl butoxide on biotransformational enzyme activities in Aedes aegypti (Diptera: Culicidae). J. Med. Entomol. 2012, 49, 614-623. [CrossRef]

46. Huang, C.-S.; Lii, C.-K.; Lin, A.-H.; Yeh, Y.-W.; Yao, H.-T.; Li, C.-C.; Wang, T.-S.; Chen, H.-W. Protection by chrysin, apigenin, and luteolin against oxidative stress is mediated by the Nrf2-dependent up-regulation of heme oxygenase 1 and glutamate cysteine ligase in rat primary hepatocytes. Arch. Toxicol. 2013, 87, 167-178. [CrossRef]

47. Oppenoorth, F.; Rupes, V.; ElBashir, S.; Houx, N.; Voerman, S. Glutathione-dependent degradation of parathion and its significance for resistance in the housefly. Pestic. Biochem. Physiol. 1972, 2, 262-269. [CrossRef]

48. Motoyama, N.; Dauterman, W. Interstrain comparison of glutathione-dependent reactions in susceptible and resistant houseflies. Pestic. Biochem. Physiol. 1975, 5, 489-495. [CrossRef]

49. Gershenzon, J.; Fontana, A.; Burow, M.; Wittstock, U.; Degenhardt, J. Mixtures of plant secondary metabolites: Metabolic origins and ecological benefits. In the Ecology of Plant Secondary Metabolites: From Genes to Global Processes; Cambridge University Press: Cambridge, UK, 2012; Volume 56.

50. Salunke, B.; Kotkar, H.; Mendki, P.; Upasani, S.; Maheshwari, V. Efficacy of flavonoids in controlling Callosobruchus chinensis (L.) (Coleoptera: Bruchidae), a post-harvest pest of grain legumes. Crop Prot. 2005, 24, 888-893. [CrossRef]

51. Djeridane, A.; Yousfi, M.; Nadjemi, B.; Maamri, S.; Djireb, F.; Stocker, P. Phenolic extracts from various Algerian plants as strong inhibitors of porcine liver carboxylesterase. J. Enzym. Inhib. Med. Chem. 2006, 21, 719-726. [CrossRef] [PubMed] 
52. Barbosa Filho, J.M.; Medeiros, K.C.P.; Diniz, M.d.F.F.; Batista, L.M.; Athayde-Filho, P.F.; Silva, M.S.; da Cunha, E.V.; Almeida, J.R.; Quintans-Júnior, L.J. Natural products inhibitors of the enzyme acetylcholinesterase. Rev. Bras. Farmacogn. 2006, 16, $258-285$. [CrossRef]

53. Praveena, A.; Sanjayan, K. Inhibition of acetylcholinesterase in three insects of economic importance by linalool, a monoterpene phytochemical. Insect Pest Manag. A Curr. Scenar. 2011, 340-345.

54. Galvão, S.S.L.; Monteiro, A.; Siqueira, E.P.; Bomfim, M.R.Q.; Dias-Souza, M.V.; Ferreira, G.F.; Denadai, A.M.L.; Santos, Á.R.; Lúcia dos Santos, V.; Souza-Fagundes, E.M. Annona glabra flavonoids act as antimicrobials by binding to Pseudomonas aeruginosa cell walls. Front. Microbiol. 2016, 7, 2053. [CrossRef] [PubMed]

55. Mostafa, I.; Abbas, H.A.; Ashour, M.L.; Yasri, A.; El-Shazly, A.M.; Wink, M.; Sobeh, M. Polyphenols from Salix tetrasperma impair virulence and inhibit Quorum sensing of Pseudomonas aeruginosa. Molecules 2020, 25, 1341. [CrossRef]

56. Nain, Z.; Mansur, F.J.; Syed, S.B.; Islam, M.A.; Azakami, H.; Islam, M.R.; Karim, M.M. Inhibition of biofilm formation, quorum sensing and other virulence factors in Pseudomonas aeruginosa by polyphenols of Gynura procumbens leaves. J. Biomol. Struct. Dyn. 2020, 1-15. [CrossRef]

57. Koley, T.K.; Khan, Z.; Oulkar, D.; Banerjee, T.; Singh, A.; Karkute, S.G.; Banerjee, K. Coupling the high-resolution LC-MS characterisation of the phenolic compounds with the antimicrobial and antibiofilm properties of helencha (Enydra fluctuans Lour.). J. Food Sci. Technol. 2021, 1-11. [CrossRef]

58. Mrabti, H.N.; Bouyahya, A.; Ed-Dra, A.; Kachmar, M.R.; Mrabti, N.N.; Benali, T.; Shariati, M.A.; Ouahbi, A.; Doudach, L.; Faouzi, M.E.A. Polyphenolic profile and biological properties of Arbutus unedo root extracts. Eur. J. Integr. Med. 2021, $42,101266$. [CrossRef]

59. Ofokansi, K.C.; Attama, A.A.; Uzor, P.F.; Ovri, M.O. Evaluation of the combined antimicrobial activity of the leaf extract of Phyllantus muellerianus with ciprofloxacin. J. Pharm Technol. Drug Res. 2013, 2, 16. [CrossRef]

60. Kumar, L.; Chhibber, S.; Harjai, K. Zingerone inhibit biofilm formation and improve antibiofilm efficacy of ciprofloxacin against Pseudomonas aeruginosa PAO1. Fitoterapia 2013, 90, 73-78. [CrossRef] [PubMed]

61. Grau, S.; Echeverria-Esnal, D.; Gómez-Zorrilla, S.; Navarrete-Rouco, M.E.; Masclans, J.R.; Espona, M.; Gracia-Arnillas, M.P.; Duran, X.; Comas, M.; Horcajada, J.P. Evolution of Antimicrobial Consumption During the First Wave of COVID-19 Pandemic. Antibiotics 2021, 10, 132. [CrossRef]

62. Tiwari Pandey, A.; Pandey, I.; Zamboni, P.; Gemmati, D.; Kanase, A.; Singh, A.V.; Singh, M.P. Traditional Herbal Remedies with a Multifunctional Therapeutic Approach as an Implication in COVID-19 Associated Co-Infections. Coatings 2020, 10, 761. [CrossRef] 